\title{
Basitleştirilmiş tasarım ilkelerinin betonarme binaların kat ötelemelerine tesiri üzerine bir inceleme
}

\author{
An investigation on the effect of simplified design principles on the storey drift of \\ RC buildings
}

\author{
Hakan Dilmaç 1,*iD \\ ${ }^{1}$ Süleyman Demirel Üniversitesi, Inşaat Mühendisliği Bölümü, 32260, Isparta, Türkiye
}

\begin{abstract}
Özet
Türkiye Bina Deprem Yönetmeliği' inde (TBDY) düzenli yerinde dökme betonarme binalar için basitleştirilmiş tasarım kuralları ayrıntılı olarak verilmektedir. Bu tasarım kurallarında, taşıyıcı sistem türüne bağlı olarak kolon ve perde elemanların kesit boyutları için ön tasarım koşulları belirtilmektedir. Çalışma kapsamında, taşıyıcı sistemi çerçeveli olan üç ve beș katlı, farklı yapısal özellikleri olan 38 adet model bina tasarımı yapılmıştır. Model binaların tasarım kuraları ve kolon elemanlarının kesit boyutları, TBDY' de belirtilen sınır şartlarını sağlayacak şekilde dikkate alınmıştır. Analizlerde, farklı deprem sınıfı, zemin türü ve bina yüksekliği kullanılarak, binalara ait basitleştirilmiş ve standart hesap yöntemleriyle elde edilen elastik taban kesme kuvvetleri hesaplanmıştır. Ayrıca, binalar ait kat ötelemeleri ve göreli kat yerdeğiştirme değerleri hesaplanmıştır. Elde edilen taban kesme kuvvetleri ve kat ötelemeleri kendi içerisinde karşılaştırılmıştır. TBDY kapsamında göreli kat ötelemeleri için belirtilen sınır şartı kontrolleri yapılmıştır. TBDY kapsamına basitleştirilmiş tasarım kuralları ile modellenen binaların göreli kat ötelemeleri için belirtilen sınır şartı çoğunlukla karşılamadığı görülmüşsür.
\end{abstract}

Anahtar kelimeler: Kat ötelemesi, Betonarme bina, Taban kesme kuvveti, Ön tasarım

\section{Giris}

Dünyada ve ülkemizde meydana gelen depremler, sürekli güncellenen deprem haritaları, insanlara depremin her an ve her yerde meydana gelebileceği gerçeğini göstermektedir. Özellikle, son otuz yıldaki depremlerin sebep olduğu maddi ve manevi bilanço göz önüne alındığında, mevcut yapı stokunun depreme karş1 dayanıklı olmadığ net bir şekilde anlaşılmaktadır. Birçok ülkede, depreme karşı dayanıklı yapı tasarımı ve mevcut yapıların deprem dayanımının tespiti için hesap esaslarının önerildiği yönetmelikler, şartnameler çıkarılmakta veya mevcut olanları güncellenmektedir [1-5]. Ülkemizde 2007 yılında yayınlanan Deprem Bölgelerinde Yapılacak Binalar Hakkında Yönetmelik [4] kapsamı genişletilerek bazı düzenlemelerle 2018 yılında TBDY [5] olarak güncellenmiştir.

Depreme dayanıklı yapı tasarımı veya mevcut binaların deprem performansının belirlenmesi için mevcut

\begin{abstract}
Simplified design rules for regular reinforced concrete (RC) buildings are given in detail in the Turkish Building Seismic Code (TBSC). Depending on the structural system type, preliminary design conditions are specified for the cross-sectional dimensions of the columns and RC shear walls. In the study, three and five-storey 38 model buildings with have different structural features and framed loadcarrier systems were designed. The design rules of the model buildings and the cross-sectional dimensions of the columns have been considered to meet the threshold conditions specified in TBSC. In the analyses, the elastic base shear forces of the RC buildings were obtained by using different earthquake class, soil type and building height. In addition, storey drifts and relative storey displacements of RC buildings were calculated. The obtained base shear forces and storey drifts were compared within themselves. Within the scope of TBSC, the specified threshold condition controls were made for the relative storey drifts. It has been observed that the buildings modeled with simplified design rules within the scope of TBCD mostly do not meet the threshold condition specified for the relative storey drifts.
\end{abstract}

Keywords: Storey drift, RC building, Base shear force, Pre-design

yönetmeliklerde öngörülen hesap esasları oldukça zaman alıcı ve zordur. Bu açıdan, betonarme binaların deprem performansının hızlı ve kolay bir şekilde değerlendirilebilmesi için birçok alternatif yöntem araştırmacılar tarafından önerilmiştir [6-12]. Önerilen bu yöntemlerde birçok farklı kabuller yapılmaktadır. Dolayısıyla, önerilen bu alternatif yöntemlerle elde edilen analiz sonuçları ile yönetmeliğin hesap esaslarına göre yapılan analizlerden elde edilen sonuçlar tamamen birbiri ile uyum sağlayamamaktadır.

Betonarme binaların tasarım aşamasında yeterli mühendislik hizmetini alması bina güvenliği açısından oldukça önemlidir. Buna bağlı olarak, TBDY' nin son kısmında düzenli yerinde dökme betonarme binalar için basitleştirilmiş tasarım kuralları verilmektedir. Bu bölüme göre belirli tasarım sınırları içerisinde kalma koşuluyla,

\footnotetext{
* Sorumlu yazar / Corresponding author, e-posta / e-mail: hakandilmac@sdu.edu.tr (H. Dilmaç)

Geliș / Recieved: 17.10.2021 Kabul / Accepted: 12.11.2021 Yayımlanma / Published: 14.01.2022

doi: 10.28948/ngmuh.1011015
} 
basitleştirilmiş hesap esasları kullanılarak binaların tasarımları kolaylaştırılmaktadır [13].

Çalışma kapsamında, TBDY' nin son kısmında yer alan taşıyıcı sistemi çerçeveli olan betonarme binalar için tasarım kurallarını ve sınır şartlarını sağlayan 3 ve 5 katlı model konut bina tasarımı yapılmıştır. Bu model binaların her biri için 5 farklı zemin türüne ve deprem tasarın sınıfına (DTS) göre spektral ivme katsayıları AFAD deprem tehlike haritasından elde edilmiştir [14]. Bu parametreler dikkate alındığında toplam 38 adet model bina analiz için tasarlanmıştır. DD-2 tasarım deprem spektrumu dikkate alınarak elde edilen elastik taban kesme kuvvetleri (standart taban kesme kuvveti) her bir bina için elde edilmiştir. Aynı zamanda, TBDY'nin son bölümünde tanımlanan basitleştirilmiş tasarım kuralları dikkate alınarak hesaplanabilecek bina taban kesme kuvvetleri de hesaplanmıştır. Her iki taban kesme kuvvetine göre kat ötelemeleri, göreli kat yerdeğiştirme değerleri hesaplanmıştır. Aynı zamanda, TBDY Bölüm 4' de belirtilen etkin göreli kat sınır şartı kontrolleri yapılmıştır. Tüm bu analizlerden elde edilen verilerle, çerçeveli taşıyıcı sistemi olan betonarme binalar için önerilen tasarım esaslarının uygunluğu araştırılmıştır.

\section{2 Çerçeveli betonarme binaların basitleştirilmiş tasarım kuralları}

TBDY' de yeni yapılacak betonarme bir binanın deprem güvenliğini sağlamak için detaylı tasarım ve hesap yöntemleri belirtilmiştir. Bu yöntemlerin uygulanmasında binaların hem düşey hem de yatay yükler altındaki davranışı esas alınarak gerekli hususlar belirtilmiştir. Bunun yanında, çerçeveli taşıyıcı sisteme sahip düzenli yerinde dökme betonarme binalar için basitleştirilmiş tasarım kuralları TBDY [5] son bölümde detaylandırılmıştır. Bu bölümde, betonarme binaların yatay yük taşıyıcı sisteminin sadece süneklik düzeyi yüksek sistemler için tasarım kuralları belirtilmiştir. Bu kurallar, taşıyıcı sistem elemanları deprem etkileri ve düşey yükler tesirine karşı yeterli moment taşıma gücü ve yeterli kesme dayanımına sahip olması için enkesitlerinin boyutlandırılması ve donatılarının belirlenmesi ile sınırlıdır. Çerçeveli taşıyıcı sisteme sahip betonarme binaların kolon elemanlarının kesit boyutlarının ön tasarımı için TBDY' de bağıntılar mevcuttur. Kolon elemanların emniyetli taşıyabileceği eksenel basınç kuvveti gereksinimi için Denklem (1), yeterli kesme kuvveti dayanımı için Denklem (2) ve yeterli yanal rijitlik sahip olması için gereken minimum kesit alanı veya boyutları Denklem (3) ile elde edilebilmektedir.

$$
\begin{gathered}
A_{c i} \geq 0.00014(g+q) \sum A_{0 i} \\
A_{c i} \geq 0.00022 . S_{D S} \cdot(g+0.3 q) \sum A_{0 i} \\
\sum\left(I_{i} / H_{i}^{2}\right) \geq 4.44 x 10^{-7} \cdot S_{D S} \cdot(g+0.3 g) \cdot \sum A_{p i}
\end{gathered}
$$

Burada, $A_{c i}$ her bir kolonun enkesit alanı, $(g+q)$ ortalama yayılı sabit ve hareketli yük değerleri toplamı $\left(15 \mathrm{kN} / \mathrm{m}^{2}\right)$ ve
$\Sigma A_{0 i}$ ise değeri ise göze alınan kolon için kolunun taşıdığ tüm katlar boyunca biriken alan paylarının toplamıdır. $S_{D S}$ değeri, kısa periyot bölgesi için tanımlanmış olan tasarım spektral ivme katsayısı ve $(g+0.3 q)$ ortalama yayılı sabit ve hareketli yük değerleri toplamını $\left(13 \mathrm{kN} / \mathrm{m}^{2}\right)$ ifade etmektedir. $I_{i}$ değeri bina zemin kat kolonlarının enkesit eylemsizlik momenti, $H_{i}$ ilgili katın zemine olan yüksekliği ve $\Sigma A_{p i}$ ise bina kat alanlarının toplamıdır. Verilen denklemlerle tasarım yapılabilmesi için olması gereken ön koşullar TBDY son bölümünde verilmiştir.

\section{1 Çerçeve sistemli betonarme model bina}

Çalışmada, taşıyıcı sistemi çerçevelerden oluşan, 5 farklı zemin tipi ve DTS' ye göre deprem parametreleri belirlenen, 3 ve 5 katlı 38 adet model bina tasarımı yapılmıştır. Binaların kat alanları eşit olup, her iki doğrultuda 4 açıklığa sahiptir. Açıklık mesafeleri 5 m olarak seçilmiştir (Şekil 1). TBDY' de belirtilen hususlar çerçevesinde, seçilen model binada herhangi bir düzensizlik bulunmamasına, kat planında binanın uzun kenarı en fazla $30 \mathrm{~m}$ uzunluğunda, uzun kenarın kısa kenara oranı ise en fazla 4 olmasına, taşıyıcı sistem eksenlerinde süreksizlik veya eksen dışına kayma bulunmamasına, en büyük kiriş açıklığının 7.5 m, en küçük açıkl $3 \mathrm{~m}$ ve her bir doğrultuda en az iki açıklık bulunmasına, binada $4 \mathrm{~m}$ den daha büyük kat yüksekliğinin bulunmamasına ve döşeme kalınlığının en az $150 \mathrm{~mm}$ olmasına dikkat edilerek tasarımları yapılmıştır. En küçük kolon boyutu 300x300 mm olarak dikkate alınmıştır. Seçilen model binaların tasarımında beton sınıfı C25 olarak dikkate alınmıştır.

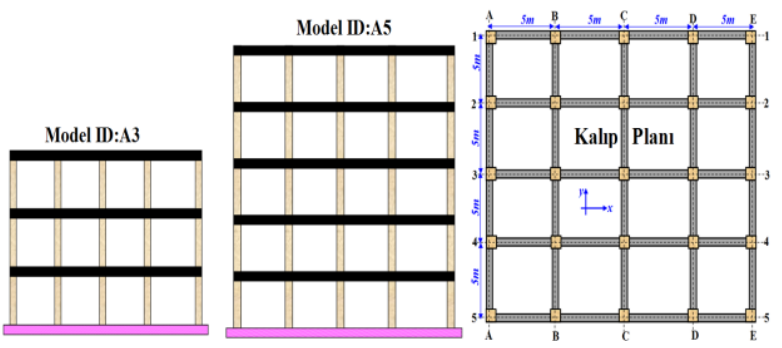

Şekil 1. Model binalara ait kalıp planı ve en kesit görünümleri

\section{Yöntem}

Çalışmada, kalıp planı ve en kesit görünüşleri verilen düzenli yerinde dökme çerçeveli model betonarme binaların standart ve basitleştirilmiş taban kesme kuvvetleri, kat ötelemeleri ve sınır koşullarının kontrolü için ZA, ZB, ZC, $Z D$ ve $Z E$ zemin türlerine ait deprem spektral ivme katsayıları dikkate alınarak model binaların kolon boyutları belirlenmiştir. Aynı zamanda, deprem tasarım sınıfı (DTS)' ye göre ayrıca spektral ivme katsayıları dikkate alınmıştır (Bk. Tablo 1).

DD-2 için verilen spektral ivme katsayıları, kolon elamanların yeterli kesme dayanımına sahip olması ve yeterli yanal rijitliği sağlaması açısından öngörülen en küçük kesit boyut hesabında kullanılmakla beraber, DD-3 için verilen spektral ivme katsayıları etkin göreli kat sınır koşulunun tahkiki için gerekmektedir. İşlemlerin daha iyi anlaşılabilmesi için tasarlanan A3 ve A5 model binasının 
aynı tip kolonları aynı adlandırılmıştır. Köşe kolonlar "C", kenar kolonlar "S" ve orta kolonlar "M" ile ifade edilmiştir. Denklem (1), Denklem (2), ve Denklem (3)' de verilen her üç koşulu sağlayan kolon boyutları, zemin sınıfı ve DTS' ye göre Tablo 2' de verilmiştir. Model binaların, simetrikliğinden yararlanarak sadece $\mathrm{x}$ - doğrultusu için hesaplamalar yapılmıştır. Bu yüzden, kolon elemanların kısa kenarı sabit $(b=0.3 m)$ tutularak diğer kesit boyutu $(h)$, verilen ön tasarım şartlarını sağlayacak şekilde hesaplanmıştır.

Tablo 1. Tasarım spektral ivme katsayıları

\begin{tabular}{clllll}
\hline \multirow{2}{*}{ DTS } & Zemin & $\begin{array}{l}\text { Sds (DD- } \\
\text { 2) }\end{array}$ & $\begin{array}{l}\text { Sd1 } \\
(\text { DD-2 })\end{array}$ & $\begin{array}{l}\text { Sds } \\
(\text { DD-3) }\end{array}$ & $\begin{array}{l}\text { Sd1 } \\
(\mathrm{DD}-3)\end{array}$ \\
\hline & ZA & 1.322 & 0.362 & 0.519 & 0.124 \\
& ZB & 0.796 & 0.163 & 0.309 & 0.086 \\
- & ZC & 1.738 & 0.599 & 0.706 & 0.205 \\
& ZD & 1.083 & 0.517 & 0.561 & 0.260 \\
& ZE & 0.957 & 0.637 & 0.626 & 0.340 \\
& ZA & 0.742 & 0.182 & 0.297 & 0.071 \\
$\sim$ & ZB & 0.598 & 0.130 & 0.236 & 0.056 \\
& ZC & 0.657 & 0.192 & 0.257 & 0.079 \\
& ZD & 0.503 & 0.204 & 0.189 & 0.077 \\
& ZE & 0.562 & 0.244 & 0.178 & 0.092 \\
& ZA & 0.402 & 0.132 & 0.165 & 0.044 \\
& ZB & 0.422 & 0.096 & 0.167 & 0.039 \\
& ZC & 0.415 & 0.199 & 0.148 & 0.046 \\
& ZD & 0.330 & 0.180 & 0.130 & 0.094 \\
& ZE & 0.499 & 0.286 & 0.204 & 0.176 \\
& ZA & 0.231 & 0.098 & 0.098 & 0.044 \\
& ZB & 0.309 & 0.103 & 0.133 & 0.048 \\
& ZC & 0.211 & 0.097 & 0.079 & 0.042 \\
& ZD & 0.261 & 0.156 & 0.091 & 0.062 \\
\hline
\end{tabular}

Tablo2. Tasarım sınır şartlarını sağlayan en küçük kolon boyutu

\begin{tabular}{|c|c|c|c|c|c|c|c|}
\hline$\stackrel{2}{0}$ & $\begin{array}{c}\text { Kolon } \\
\text { ID }\end{array}$ & $\begin{array}{c}\sum \text { Aoi } \\
\left(\mathrm{m}^{2}\right)\end{array}$ & $\begin{array}{l}\mathrm{h}(\mathrm{m}) \\
(\mathrm{ZA})\end{array}$ & $\begin{array}{l}\mathrm{h}(\mathrm{m}) \\
(\mathrm{ZB})\end{array}$ & $\begin{array}{l}\mathrm{h}(\mathrm{m}) \\
(\mathrm{ZC})\end{array}$ & $\begin{array}{l}\mathrm{h}(\mathrm{m}) \\
(\mathrm{ZD})\end{array}$ & $\begin{array}{l}\mathrm{h}(\mathrm{m}) \\
(\mathrm{ZE})\end{array}$ \\
\hline 1 & A3_C & 18.8 & 1.49 & 1.49 & 1.49 & 1.49 & 1.49 \\
\hline 2 & A3_C & 18.8 & 1.23 & 1.23 & 1.23 & 1.23 & 1.23 \\
\hline 3 & A3_C & 18.8 & 1.00 & 1.00 & 1.00 & 1.00 & 1.00 \\
\hline 4 & A3_C & 18.8 & 0.83 & 0.83 & 0.83 & 0.83 & - \\
\hline 1 & A3_S & 37.5 & 1.49 & 1.49 & 1.49 & 1.49 & 1.49 \\
\hline 2 & A3_S & 37.5 & 1.23 & 1.23 & 1.23 & 1.23 & 1.23 \\
\hline 3 & A3_S & 37.5 & 1.00 & 1.00 & 1.00 & 1.00 & 1.00 \\
\hline 4 & A3_S & 37.5 & 0.83 & 0.83 & 0.83 & 0.83 & - \\
\hline 1 & A3_M & 75 & 1.49 & 1.49 & 1.49 & 1.49 & 1.49 \\
\hline 2 & A3_M & 75 & 1.23 & 1.23 & 1.23 & 1.23 & 1.23 \\
\hline 3 & A3_M & 75 & 1.00 & 1.00 & 1.00 & 1.00 & 1.00 \\
\hline 4 & A3_M & 75 & 0.83 & 0.83 & 0.83 & 0.83 & - \\
\hline 1 & A5_C & 31.3 & 1.76 & 1.76 & 1.76 & 1.76 & 1.76 \\
\hline 2 & A5_C & 31.3 & 1.45 & 1.45 & 1.45 & 1.45 & 1.45 \\
\hline 3 & A5_C & 31.3 & 1.19 & 1.19 & 1.19 & 1.19 & 1.19 \\
\hline 4 & A5_C & 31.3 & 0.99 & 0.99 & 0.99 & 0.99 & - \\
\hline 1 & A5_S & 62.5 & 1.76 & 1.76 & 1.76 & 1.76 & 1.76 \\
\hline 2 & A5_S & 62.5 & 1.45 & 1.45 & 1.45 & 1.45 & 1.45 \\
\hline 3 & A5_S & 62.5 & 1.19 & 1.19 & 1.19 & 1.19 & 1.19 \\
\hline 4 & A5_S & 62.5 & 0.99 & 0.99 & 0.99 & 0.99 & - \\
\hline 1 & A5_M & 125 & 1.76 & 1.76 & 1.76 & 1.76 & 1.76 \\
\hline 2 & A5_M & 125 & 1.45 & 1.45 & 1.45 & 1.45 & 1.45 \\
\hline 3 & A5_M & 125 & 1.19 & 1.19 & 1.19 & 1.19 & 1.19 \\
\hline 4 & A5_M & 125 & 0.99 & 0.99 & 0.99 & 0.99 & - \\
\hline
\end{tabular}

Düzenli betonarme binaların ön tasarımı hususunda TBDY' de verilen bağıntılar yardımı ile kolon kesit boyutları verilmektedir. Ancak bu boyutların, binanın deprem performans analizinde yeterli olup olmayacağı hususunda herhangi bir durum ifade edilmemektedir. Yazar tarafından yapılan bir çalışmada [14], sınırlı parametreler dikkate alınarak, ön tasarımında esas kriterleri sağlayan kolon boyutları ile deprem performansı arasında ilişki ortaya konulmuştur. Bu çalışmada, herhangi bir dinamik analiz yapılmaksızın, her DTS ve zemin sınıfına göre belirlenen her bir model binanın kat ötelemeleri ve etkin göreli kat sınır koşulu araştırılmıştır.

TBDY kapsamında DD-2 deprem düzeyi spektrum davranışına karşılık gelen elastik taban kesme kuvveti Denklem (4)' de ve yöntemliğin son bölümünde belirtilen basitleştirilmiş taban kesme kuvveti Denklem (5)' de verildiği şekli ile elde edilmiştir.

$$
\begin{gathered}
V_{t e}^{x}=m_{t} \cdot S_{a R}\left(T_{p}^{x}\right) \\
V_{t}=\frac{S_{D S} \cdot W_{t}}{R_{a}(T)}
\end{gathered}
$$

Standart taban kesme kuvveti hesabında (Bk. Denklem (4)) yer alan azaltılmış tasarım spektral ivme katsayısı $\left(S_{a R}(T)\right)$, yatay elastik tasarım ivmesi $\left(S_{a e}(T)\right)$ ve deprem yükü azaltma katsayısına $\left(R_{a}(T)\right)$ ye göre hesaplanmaktadır. Ancak, Denklem (5)' de verilen basitleştirilmiş taban kesme kuvveti hesabında $R_{a}(T)=4$ alınması zorunlu kılınmıştır. Diğer hesap ayrıntıları detaylı olarak TBDY' de belirtilmektedir. Model binaların her iki taban kesme kuvvetlerine göre göreli kat ötelemeleri $\left(\Delta d_{i}\right)$, etkin göreli kat ötelemeleri $\left(\delta_{i}\right), \lambda$ katsayısı ve sınır şartı kontrolü için hesap verileri sırası ile Denklem (6), Denklem (7), Denklem (8) ve Denklem (9) ile hesaplanmıştır. Betonun elastisite modülü $\left(E_{c}\right)$ değeri Denklem (10) verildiği gibidir. Ayrıntılı hesap içerikleri TBDY Bölüm 4.9' de belirtilmektedir.

$$
\begin{gathered}
\Delta d_{i}=\frac{V_{i} h_{i}^{2}}{12 E_{c} \sum D_{i}} \\
\delta_{i}=\frac{R}{I} \Delta d_{i} \\
\lambda=\frac{S_{a e}(T)^{D D-3}}{S_{a e}(T)^{D D-2}} \\
\lambda \frac{\delta_{i, m a k s}}{h_{i}} \leq 0.008 \kappa \\
E_{c}=5000 \sqrt{f_{c k}}
\end{gathered}
$$




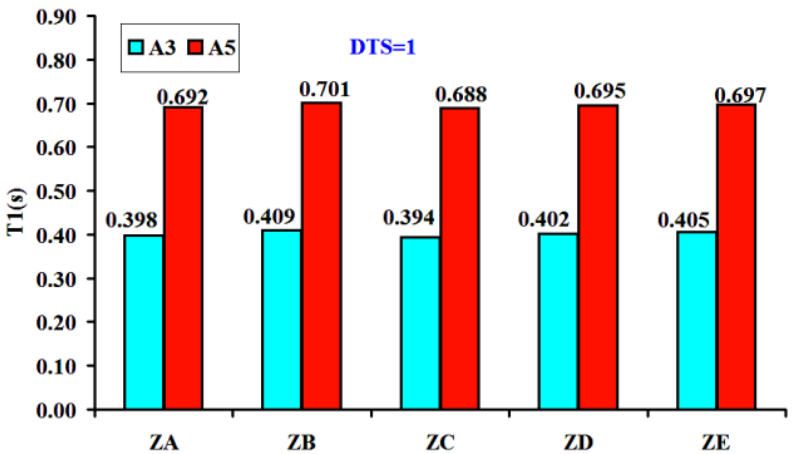

(a)

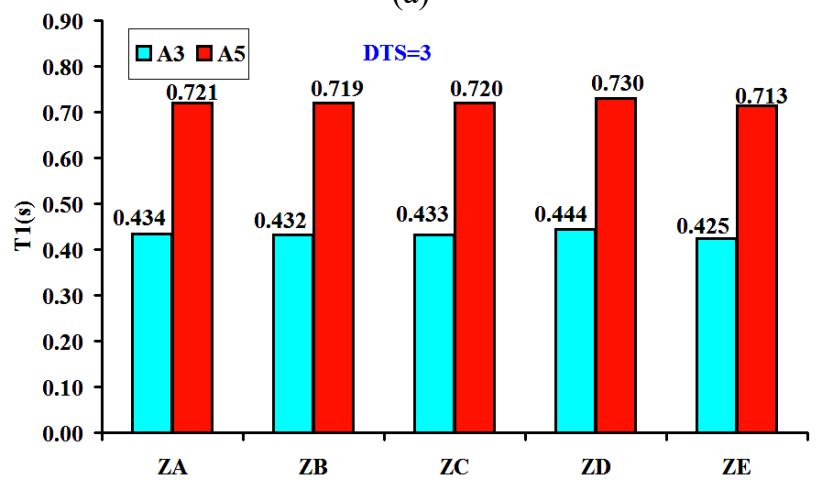

(c)

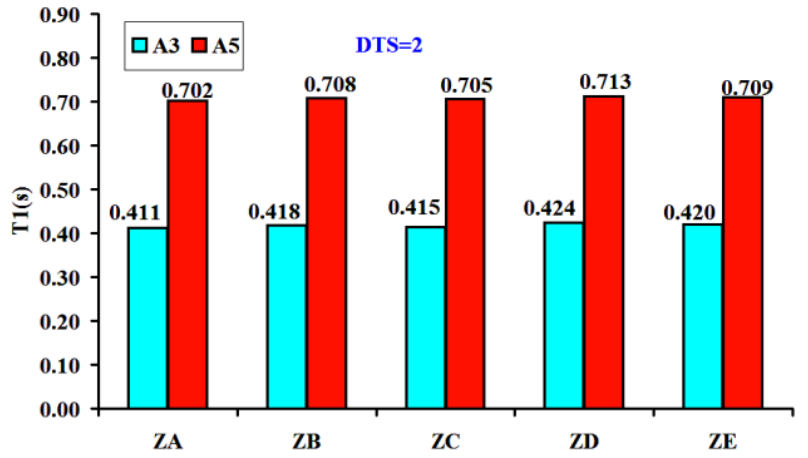

(b)

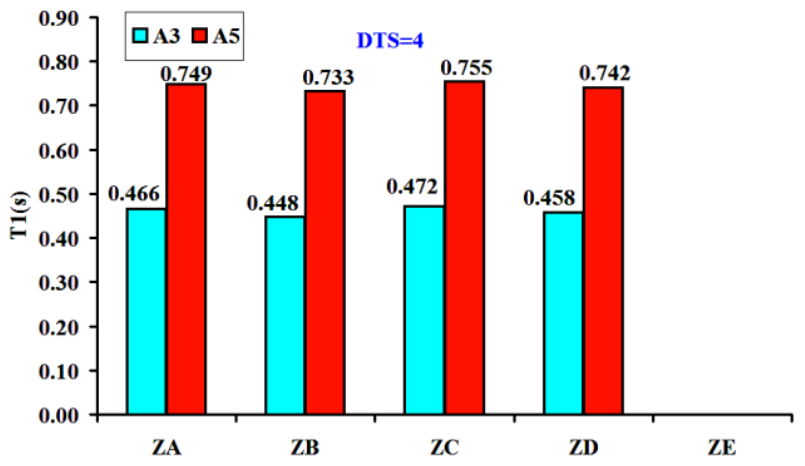

(d)

Şekil 2. Model binaların DTS ve zemin sınıfına göre periyot değişimi

$\mathrm{Bu}$ denklemlerde; $V_{i}$ kat kesme kuvveti, $h_{i}$ kat yüksekliği, $D_{i}$ kolonların rijitlik katsayıları olup, TBDY' de hesap ayrıntıları belirtilmiştir. $R$ taşıyıcı sistem davranış katsayısını, $I$ bina önem katsayısını ifade etmektedir. Aynı zamanda $\kappa$ katsayısı betonarme binalarda $\kappa=1.0^{\prime}$ e eşittir. $\lambda$ katsayısı binanın gözönüne alınan deprem doğrultusundaki hakim titreşim periyodu için TBDY Bölüm 2.2'de tanımlanan DD-3 deprem yer hareketine göre hesaplanan elastik tasarım spektral ivmesinin, DD-2 deprem yer hareketinin elastik tasarım spektral ivmesi'ne oranıdır.

\section{Analiz sonuçları}

Betonarme bir binanın gerek elastik gerek elastik ötesi davranışının analizi için binanın yerel zemin özelliklerine göre deprem parametrelerinin belirlenmesi gerekmektedir. Binaların deprem parametreleri, önceki yönetmeliklerde binaların bulunduğu bölgelerin deprem derecelerine göre belirlenirken, TBDY kapsamında neredeyse her bina parseli özelinde tayin edilmektedir. Çalışma kapsamında, farklı deprem tasarım sınıflarının $S_{D S}$ değerlerine göre basitleştirilmiş taban kesme kuvvetleri ve standart deprem spektrumundan elde edilen taban kesme kuvvetleri elde edilmiştir. Çalışmanın içeriğinde belirtildiği üzere, normal bir tasarım ve basitleştirilmiş tasarım ile modellenen bir binanın kat ötelemelerindeki farklılıkların ve etkin göreli kat sınır şartını ne derece sağlandığının araştırılması amaçlanmaktadır. Dolayısıyla, hem standart hem de basitleştirilmiş taban kesme kuvveti değerlerinin değişimi etken rol oynayacaktır. Taban kesme kuvvetinin de belirlenmesinde bina periyodu oldukça etkili bir parametredir. Çalışmada belirlenen parametrelere, kolon kesit boyutları dikkate alınarak hesaplanan bina periyotları Şekil 2' de verilmiştir. Deprem tasarım sınıfı ve kat adedine göre Denklem 4 ve Denklem 5' den elde edilen taban kesme kuvvetlerinin değişimi Şekil 3' deki gibidir.

Aynı zemin için farklı oranların çıkması DTS değerlerinin farklılığından kaynaklanmaktadır. Analizlerde kısa periyot tasarım spektral ivme katsayısı $\left(S_{D S}\right)$; DTS=1 için $S_{D S}>0.75$, DTS $=2$ için $0.75>S_{D S}>0.50$, DTS=3 için $0.50>S_{D S}>0.33$ ve DTS $=4$ için $0.33>S_{D S}$ değerlerine uygun olarak seçilmiştir.

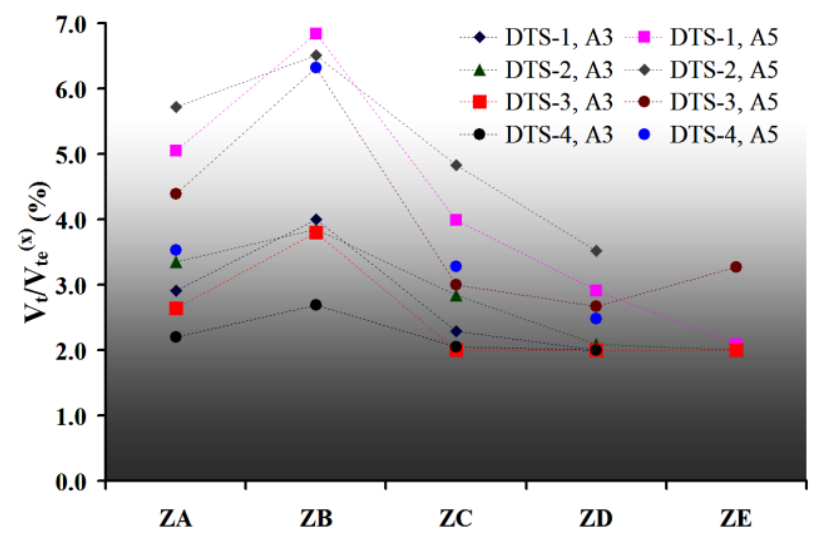

Şekil 3. Tasarım kesme kuvvetlerinin dağılımı 
Tablo 3. Model binaların $\mathrm{V}_{\mathrm{t}}$ ve $\mathrm{V}_{\text {te }}$ değerleri

\begin{tabular}{|c|c|c|c|c|c|c|c|c|c|c|c|}
\hline \multirow[b]{2}{*}{$\mathrm{V}(\mathrm{kN})$} & \multirow[b]{2}{*}{ DTS } & \multicolumn{2}{|c|}{$\mathrm{ZA}$} & \multicolumn{2}{|c|}{$\mathrm{ZB}$} & \multicolumn{2}{|c|}{$\mathrm{ZC}$} & \multicolumn{2}{|c|}{ ZD } & \multicolumn{2}{|c|}{$\mathrm{ZE}$} \\
\hline & & A3 & A5 & A3 & A5 & A3 & A5 & A3 & A5 & A3 & A5 \\
\hline \multirow{4}{*}{$\mathrm{V}_{\mathrm{t}}$} & DTS-1 & 6702.5 & 11170.9 & 4035.7 & 6726.2 & 8811.7 & 14686.1 & 5490.8 & 9151.4 & 4852.0 & 8086.7 \\
\hline & DTS-2 & 3761.9 & 6269.9 & 3031.9 & 5053.1 & 3331.0 & 5551.7 & 2550.2 & 4250.4 & 2849.3 & 4748.9 \\
\hline & DTS-3 & 2038.1 & 3396.9 & 2139.5 & 3565.9 & 2104.1 & 3506.8 & 1673.1 & 2788.5 & 2529.9 & 4748.9 \\
\hline & DTS-4 & 1171.2 & 1952.0 & 1566.6 & 3565.9 & 1069.8 & 1783.0 & 1323.3 & 2205.5 & - & - \\
\hline \multirow{4}{*}{$\mathrm{V}_{\mathrm{te}}$} & DTS-1 & 2303.0 & 2211.1 & 1009.3 & 983.1 & 3850.3 & 3676.1 & 2745.4 & 3144.4 & 2426.0 & 3862.3 \\
\hline & DTS-2 & 1121.7 & 1095.2 & 788.3 & 776.2 & 1172.9 & 1150.5 & 1218.6 & 1209.1 & 1424.7 & 1453.2 \\
\hline & DTS-3 & 771.1 & 773.5 & 563.7 & 564.1 & 1052.0 & 1168.2 & 836.6 & 1042.5 & 1265.0 & 1453.2 \\
\hline & DTS-4 & 533.4 & 552.9 & 583.4 & 564.1 & 520.7 & 543.0 & 661.6 & 888.7 & - & - \\
\hline
\end{tabular}

Elastik taban kesme kuvvetinin hem standart hesabında hem de basitleștirilmiş tasarım kuralları çerçevesinde TBDY' de önerilmiş kuvvet hesabında deprem tasarım sınıflarına göre belirtilen $S_{D S}$ değerleri etkin bir parametredir. Çalışma kapsamında, DTS değerleri için belirlenen $S_{D S}$ aralıkları dikkate alınarak, $S_{D S}$ değerleri deprem tehlike haritası [14] üzerinde rastgele yerlerden seçilmiştir. $\mathrm{Bu}$ yerlerden elde edilen deprem parametreleri doğrultusunda taban kesme kuvvetlerinin değerlerinde farklılıklar görülebilmektedir. Aynı şekilde, bina periyodunun taban kesme kuvvetinin kat ve zemin türüne göre değişiminde önemli etkiye sahip olduğu anlaşılmaktadır. Model bina hakim titreşim periyotlarının $\left(T_{1}\right)$, spektrum köşe koordinatlarının $\left(T_{A}, T_{B}\right)$ periyotlarının arasında kalmasi ile $T_{1}>T_{B}$ durumunda taban kesme kuvvetlerinde büyük değişiklikler görülebilmektedir. Seçilen model binaların yapısal ve karakteristik yapıları farklı seçildiği için, taban kesme kuvvetlerinde farklılıkların görülmesi olağan olmaktadır. Kat adedi, zemin sınıfı ve DTS değerlerine göre basitleştirilmiş hesap ile elde edilen taban kesme kuvveti $\left(V_{t}\right)$ ve eşdeğer deprem yükü hesabı ile elde edilen standart taban kesme kuvveti $\left(V_{t e}\right)$ değerleri Tablo 3' de verilmiştir. Tablo 3 ve Şekil 3' de görüleceği üzere DTS=4 ve ZE için herhangi bir değer hesab1 yapılmamıştır. Bunun sebebi, DTS=4 için $S_{D S}<0.33$ şartını sağlayan bir bölgenin hemen hemen hiç olmamasıdır. Bina ağırlığı artıkça taban kesme kuvvetlerinin artması olağan görülmektedir. $S_{D S}$ değerinin artması ile her iki taban kesme kuvvetinde artışların görüldüğü anlaşılmaktadır. Bazı modellerde 3 ve 5 katlı binaların taban kesme kuvvetlerinde bina ağırlıkları ile periyot değerlerinin farkı fazla olmasına rağmen, bina deprem spektrum $T_{B}$ köşe periyot değerinden sonra ani değişim görünmektedir. Bu yüzden taban kesme kuvvetlerin birbirine yakın olarak çıkabilmektedir. Ancak, $V_{t}$ ve $V_{t e}$ arasındaki fark Tablo 3 ve Şekil 3' de belirgin bir şekilde göze çarpmaktadır.

Bina taban kesme kuvvetlerinin birbirinden farklı olmasının doğal sonucu olarak kat ötelemeleri, göreli kat ötelemeleri değerlerinde farklılıkların oluşması tahmin edilebilecek bir sonuçtur. A3 ve A5 modellerine ait rölatif kat öteleme değerleri oransal olarak sırası ile Şekil 4.a ve Şekil 4.b verilmiştir. Buradaki rölatif kat ötelemesi değerleri $\left(\delta_{i}\right), V_{t}$ ve $V_{t e}$ kuvvetlerine göre hesaplanan göreli kat ötelemelerinin kat yüksekliğine oranıdır. Anlaşılacağ1 üzere, $V_{t}$ elastik kuvvetleri, $V_{t e}$ kuvvetlerine göre daha büyük sonuçlar vermesinden dolayı, toplam kat ötelemeleri veya rölatif kat ötelemelerini de büyük oranda etkilemektedir. $\mathrm{Bu}$ farklılık daha ziyade $\mathrm{ZB}$ ve $\mathrm{ZA}$ zemin türlerinde meydana gelmektedir. Aynı zamanda, DTS=1 ve DTS=2 de tüm zemin sınıfları için daha büyük öteleme farklılıkları meydana gelmektedir. ZE' de spektral ivme katsayısı çok küçük olduğu için taban kesme kuvvetlerinin oluşturduğu rölatif kat ötelemeleri birbirine oldukça yakın çıkmaktadır.

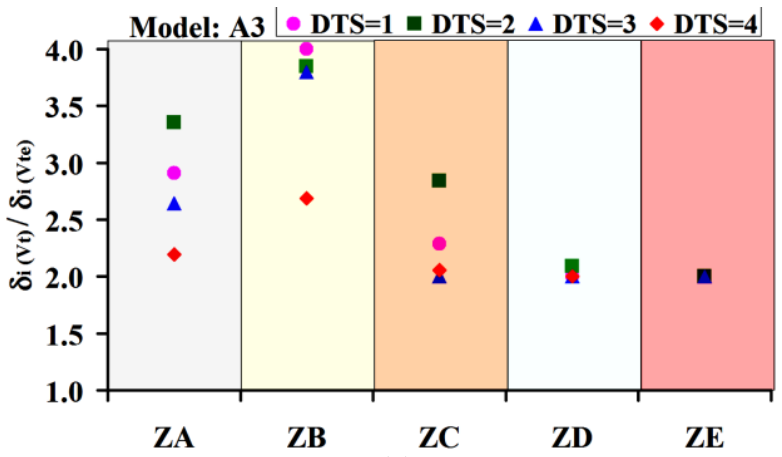

(a)

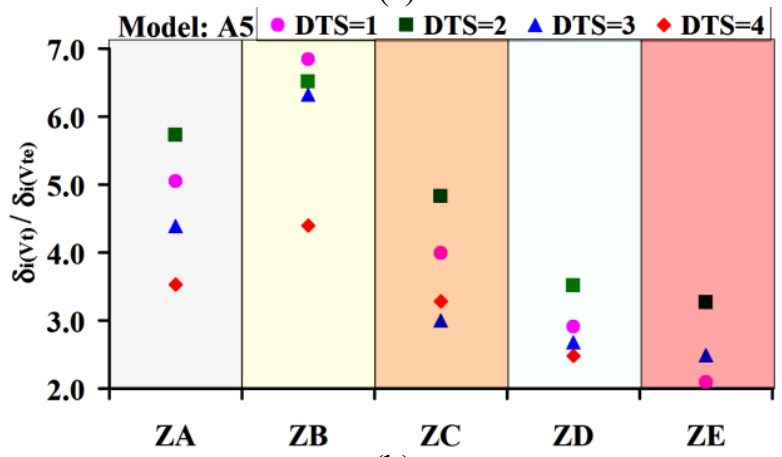

(b)

Şekil 4. Rölatif kat ötelemelerin değişimi

TBDY, Bölüm 4.9.1.3' de belirtilen esaslar doğrultusunda, betonarme binaların her kat seviyesi için etkin göreli kat ötelemeleri hesaplanarak en büyük değeri tespit edilir. Belirlenen bu değer, DD-2 deprem düzeyi elastik tasarım spektral ivme katsayısının, DD-3 deprem düzeyi elastik tasarım spektral ivme katsayısına oranının kat yüksekliğine bölümü ile çarpılır. Bu çarpım sonucu $0.008 \kappa$ değeri ile karşılaştırılarak etkin göreli kat öteleme kontrolü yapılır. Buradaki $\kappa$ değeri betonarme binalar için 1 olarak alınır. Eğer, bulunan oran verilen sınır şarttan küçük ise bina öteleme açısından emniyetli olduğu TBDY şartlarında ifade edilebilir. 
Çalışmada modellenen 38 adet betonarme bina için etkin göreli kat kontrolleri yapılmıştır. A3 ve A5 model binalarının etkin göreli kat öteleme sınır şartı kontrolü için elde edilen sonuçlar sırası ile Şekil 5 ve Şekil 6' da verilmektedir.

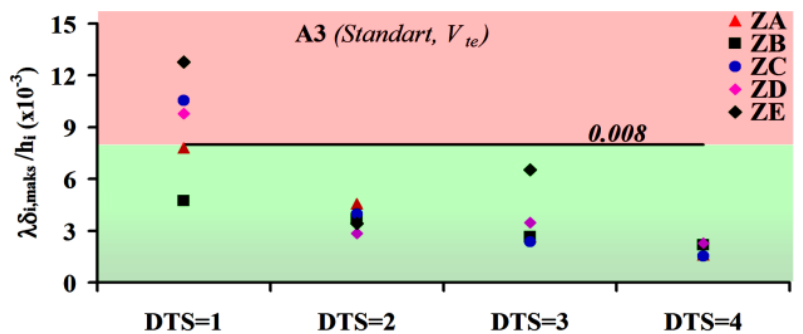

(a)

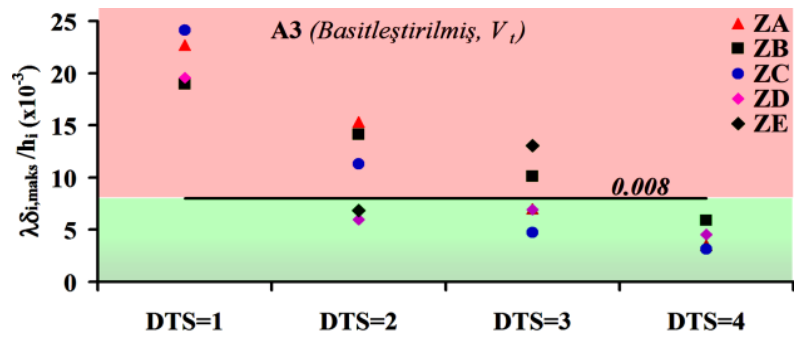

(b)

Şekil 5. Model A3 için etkin göreli kat sınır kontrolü

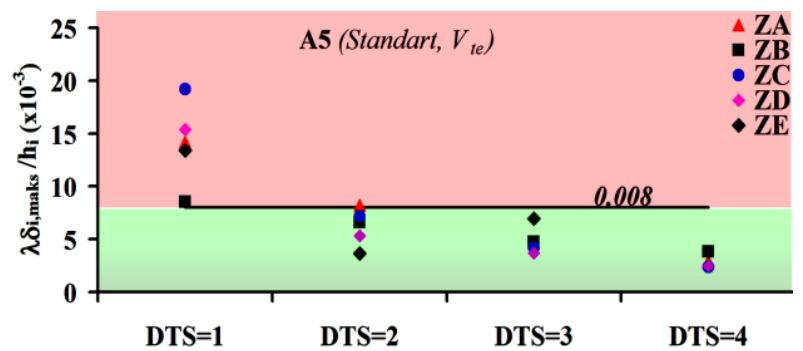

(a)

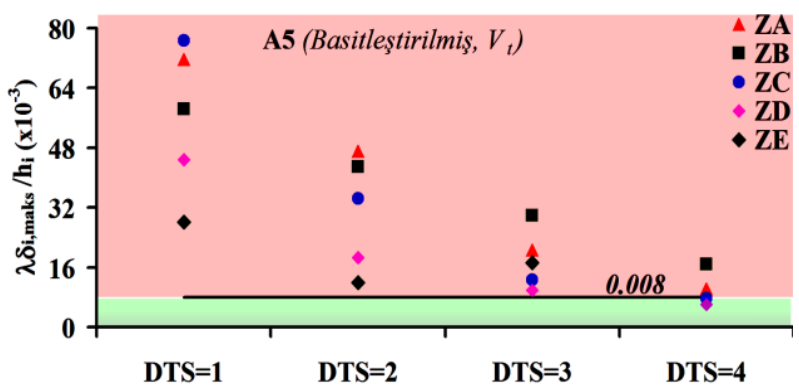

(b)

Şekil 6. Model A5 için etkin göreli kat sınır kontrolü

Basitleştirilmiş hesap ile elde edilen taban kesme kuvveti, standart hesapla elde edilen elastik taban kesme kuvvetinde daha büyük olması neticesinde, etkin göreli kat değerlerinde oldukça farklılıklar meydana gelmektedir. $V_{t e}$ kuvveti esas alındığında, hem A3 hem de A5 modelinde çoğu model için etkin göreli kat ötelemeleri cihetinden sınır şartı sağladığı görülmektedir. Ancak, $V_{t}$ kuvveti esas alınarak hesaplanan etkin göreli kat ötelemelerinin birçoğunun sınır şartın üzerinde sonuç verdiği ortaya çıkmaktadır. Çalışmada tasarlanan 38 model binaya ait sınır şartı kontrolü ve etkin göreli kat ötelemeleri değerleri Tablo 4' de verilmiştir.

Tablo 4. Etkin göreli kat değerleri ve sınır şartı kontrolü

\begin{tabular}{|c|c|c|c|c|c|c|}
\hline 目 & $\stackrel{2}{\omega}$ & 寻 & $\begin{array}{c}\lambda \delta_{\text {imak }} / h_{\mathrm{i}} \\
\left(\mathrm{V}_{\text {te }}\right)\end{array}$ & 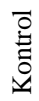 & $\begin{array}{c}\lambda \delta_{\text {imak }} / h_{\mathrm{i}} \\
\left(\mathrm{V}_{\mathrm{t}}\right)\end{array}$ & 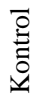 \\
\hline A3 & 1 & $\mathrm{ZA}$ & 0.0078 & $\sqrt{ }$ & 0.0227 & $X$ \\
\hline A3 & 2 & $\mathrm{ZA}$ & 0.0046 & $\sqrt{ }$ & 0.0153 & $X$ \\
\hline A3 & 3 & $\mathrm{ZA}$ & 0.0026 & $\sqrt{ }$ & 0.0070 & $\sqrt{ }$ \\
\hline A 3 & 4 & $\mathrm{ZA}$ & 0.0016 & $\sqrt{ }$ & 0.0035 & $\sqrt{ }$ \\
\hline A3 & 1 & $\mathrm{ZB}$ & 0.0047 & $\sqrt{ }$ & 0.0189 & $X$ \\
\hline $\mathrm{A} 3$ & 2 & $\mathrm{ZB}$ & 0.0037 & $\sqrt{ }$ & 0.0141 & $X$ \\
\hline A3 & 3 & $\mathrm{ZB}$ & 0.0027 & $\sqrt{ }$ & 0.0101 & $X$ \\
\hline A3 & 4 & $\mathrm{ZB}$ & 0.0022 & $\sqrt{ }$ & 0.0059 & $\sqrt{ }$ \\
\hline A 3 & 1 & $\mathrm{ZC}$ & 0.0105 & $X$ & 0.0241 & $X$ \\
\hline A 3 & 2 & $\mathrm{ZC}$ & 0.0040 & $\sqrt{ }$ & 0.0113 & $X$ \\
\hline A3 & 3 & $\mathrm{ZC}$ & 0.0024 & $\sqrt{ }$ & 0.0047 & $\sqrt{ }$ \\
\hline $\mathrm{A} 3$ & 4 & $\mathrm{ZC}$ & 0.0015 & $\sqrt{ }$ & 0.0032 & $\sqrt{ }$ \\
\hline A3 & 1 & $\mathrm{ZD}$ & 0.0098 & X & 0.0196 & $X$ \\
\hline A3 & 2 & $\mathrm{ZD}$ & 0.0029 & $\sqrt{ }$ & 0.0060 & $\sqrt{ }$ \\
\hline $\mathrm{A} 3$ & 3 & $\mathrm{ZD}$ & 0.0035 & $\sqrt{ }$ & 0.0069 & $\sqrt{ }$ \\
\hline $\mathrm{A} 3$ & 4 & $\mathrm{ZD}$ & 0.0023 & $\sqrt{ }$ & 0.0045 & $\sqrt{ }$ \\
\hline A3 & 1 & $\mathrm{ZE}$ & 0.0128 & $X$ & 0.0255 & $\mathrm{X}$ \\
\hline $\mathrm{A} 3$ & 2 & $\mathrm{ZE}$ & 0.0034 & $\sqrt{ }$ & 0.0068 & $\sqrt{ }$ \\
\hline A 3 & 3 & $\mathrm{ZE}$ & 0.0065 & $\sqrt{ }$ & 0.0131 & $\mathrm{X}$ \\
\hline A5 & 1 & $\mathrm{ZA}$ & 0.0142 & X & 0.0716 & $X$ \\
\hline A5 & 2 & ZA & 0.0082 & $X$ & 0.0471 & $X$ \\
\hline A5 & 3 & $\mathrm{ZA}$ & 0.0047 & $\sqrt{ }$ & 0.0206 & $X$ \\
\hline A5 & 4 & $\mathrm{ZA}$ & 0.0029 & $\sqrt{ }$ & 0.0102 & $X$ \\
\hline A5 & 1 & $\mathrm{ZB}$ & 0.0085 & $X$ & 0.0584 & $X$ \\
\hline A5 & 2 & $\mathrm{ZB}$ & 0.0066 & $\sqrt{ }$ & 0.0429 & $X$ \\
\hline A5 & 3 & $\mathrm{ZB}$ & 0.0047 & $\sqrt{ }$ & 0.0299 & $\mathrm{X}$ \\
\hline A5 & 4 & $\mathrm{ZB}$ & 0.0038 & $\sqrt{ }$ & 0.0169 & $\mathrm{X}$ \\
\hline A5 & 1 & $\mathrm{ZC}$ & 0.0192 & $X$ & 0.0767 & $X$ \\
\hline A5 & 2 & $\mathrm{ZC}$ & 0.0071 & $\sqrt{ }$ & 0.0345 & $X$ \\
\hline A5 & 3 & $\mathrm{ZC}$ & 0.0042 & $\sqrt{ }$ & 0.0126 & $X$ \\
\hline A5 & 4 & $\mathrm{ZC}$ & 0.0024 & $\sqrt{ }$ & 0.0077 & $\sqrt{ }$ \\
\hline A5 & 1 & ZD & 0.0154 & X & 0.0448 & X \\
\hline A5 & 2 & $\mathrm{ZD}$ & 0.0053 & $\sqrt{ }$ & 0.0187 & $X$ \\
\hline A5 & 3 & $\mathrm{ZD}$ & 0.0037 & $\sqrt{ }$ & 0.0099 & $\mathrm{X}$ \\
\hline A5 & 4 & $\mathrm{ZD}$ & 0.0024 & $\sqrt{ }$ & 0.0061 & $\sqrt{ }$ \\
\hline A5 & 1 & $\mathrm{ZE}$ & 0.0134 & $\mathrm{X}$ & 0.0281 & $X$ \\
\hline A5 & 2 & $\mathrm{ZE}$ & 0.0036 & $\sqrt{ }$ & 0.0119 & $X$ \\
\hline A5 & 3 & $\mathrm{ZE}$ & 0.0069 & $\sqrt{ }$ & 0.0173 & X \\
\hline
\end{tabular}

\section{Sonuçlar}

TBDY' nin son bölümünde yer alan düzenli yerinde dökme betonarme binalar için basitleștirilmiş tasarım kuralları yer almaktadır. Çalışma kapsamında, bu tasarım kurallarını asgari düzeyde sağlayacak iki adet 3 ve 5 katlı, 4 açıklıklı taşıyıcı sistemi çerçevelerden meydana gelen model binaların tasarımı yapılmıştır. Kolon elemanların eksenel basınç, yeterli kesme kuvveti ve yeterli yanal rijitliği sağlaması için TBDY' de ön görülen en küçük kolon kesit boyutları dikkate alınarak her bir model binanın tasarımı yapılmıştır. Farklı zemin ve deprem sınıfları dikkate alınarak model binaların farklı varyasyonları ile toplamda 38 adet model bina oluşturulmuştur. TBDY' de 
Bölüm 4.7' de ifade edilen her bir spektrum için elde edilen eşdeğer deprem yükü, yani elastik taban kesme kuvveti değerleri ile TBDY' de Bölüm 17.5' de ön tasarım esaslarına bağlı kalmak şartı ile kullanılabilecek basitleştirilmiş taban kesme kuvveti hesabı ayrı ayrı yapılmıştır. Basitleştirilmiş taban kesme kuvveti hesabında, deprem yükü azaltma katsayı değeri $R_{a}=4$ alınması zorunlu kılındığından dolayı, basitleştirilmiş taban kesme kuvveti, eşdeğer deprem yükü değerinden oldukça fazla çıkmaktadır. $\mathrm{Bu}$ farklılıktan dolayı, bina kat ötelemeleri ve göreli kat ötelemelerinde ciddi farklılıklar oluştuğu göz önüne serilmiştir. Model binaların kolon ve kiriş kesitleri aynı olmasına rağmen, dikkate alınan her iki taban kesme kuvvetinin etkin göreli kat değerlerinde büyük oranda aynı etkiyi yapmadığı görülmüştür. Standart hesapla elde edilen taban kesme kuvveti dikkate alınarak yapılan etkin göreli kat sınır şartını model binaların \%76 sağlarken, \%24'ü sağlamamaktadır. Basitleştirilmiş hesapla elde edilen taban kesme kuvveti dikkate alınarak yapılan etkin göreli kat sınır şartını model binaların \%28 sağlarken, \%72'ü sağlamamaktadır.

\section{Çıkar çatışması}

Yazar çıkar çatışması olmadığını beyan etmektedir.

\section{Benzerlik oranı (iThenticate): $\% 7$}

\section{Kaynaklar}

[1] ATC (Applied Technology Council), Seismic evaluation and retrofit of concrete buildings. ATC-40, Rep. No. SSC 96-01. West Sacramento, CA: California Seismic Safety Commission, 1996.

[2] FEMA 273, NEHRP Guidelines For The Seismic Rehabilitation of Buildings. Developed by the Building Seismic Safety Council for the Federal Emergency Management Agency, Washington, D.C., USA, 1997.

[3] FEMA-356, Prestandart and Commentary for Seismic Rehabilitation of Buildings. Washington,D.C., 2000.

[4] DBYBHY, Deprem Bölgelerinde Yapılacak Binalar Hakkında Yönetmelik. Bayındırlık ve İskân Bakanlığı, Ankara, 2007.

[5] TBDY, Türkiye Bina Deprem Yönetmeliği. Türkiye Cumhuriyeti İçişleri Bakanlığı, AFAD Yönetimi Başkanlığı, Ankara, 2018.
[6] A.C. Pay, A new methodology for the seismic vulnerability assessment of existing buildings in Turkey. M.S. dissertation, Dept. of Civil Engineering, Middle East Technical Univ., Graduate School of Natural and Applied Sciences, Turkey, 2001.

[7] H. Tekeli, H. Dilmac, F. Demir, M. Gencoglu, and K. Guler, Shear stress indicator to predict seismic performance of residential RC buildings. Computers and $\quad$ Concrete, 283-291, 2017.https://doi.org/10.12989/cac .2017.19.3.283.

[8] H. Dilmaç, Preliminary assessment approach to predict seismic vulnerability of existing low and midrise RC buildings. Bulletin of Earthquake Engineering, 18(7), 3101-3133, 2020. https://doi.org/10.1007/s10518-020-00809-z.

[9] A. Gündoğay, H. Ulutaş ve H. Tekeli, Mevcut atölye binalarının deprem güvenliğin incelenmesi. DÜMF Mühendislik Dergisi, 10:2, 755-768, 2019. https://doi.org/10.24012/dumf.432136.

[10] A. Yakut, Capacity related properties of RC frame buildings in Turkey. J. Earthquake Engineering, 12 (S2): 265-272,2008. https://doi.org/10.1080/ 13632460802014295.

[11] P. Gülkan and M. A. Sozen, Procedure for determining seismic vulnerability of building structures. ACI Structural Journal, 96 (3): 336-342, 1999.

[12] B. Balun, Ö.F. Nemutlu ve A. Sar1, TBDY 2018 Basitleştirilmiş Tasarım Kurallarının Taban Kesme Kuvvetine Etkisinin İncelenmesi.Türk Doğa ve Fen Dergisi 9.Özel Say1: 173-181, 2020.https://doi.org/ 10.46810/tdfd.749257.

[13] Türkiye Deprem Tehlike Haritası, AFAD Başkanlığı. https://deprem.afad.gov.tr/deprem-tehlike-haritasi Erişim tarihi: 01.04.2020.

[14] H. Dilmaç, Çerçeveli betonarme binaların TBDY kapsamında ön tasarımı. 3.International Symposium of Engineering Applications on Civil Engineering and Earth Sciences, sayfa 103-110, Karabük, Türkiye, 2224 Ekim 2021. 